\title{
Infestação por Cimex lectularius Linnaeus, 1758 (Hemiptera:Cimicidae), em escola rural no município de Duas Barras, estado do Rio de Janeiro, Brasil: relato de caso*

\author{
Infestation by Cimex lectularius Linnaeus, 1758 (Hemiptera: Cimicidae) \\ at a rural school in the Municipality of Duas Barras, \\ in the State of Rio de Janeiro, Brazil: a case report
}

\author{
Dalton Garcia de Mattos Júnior, ${ }^{* *}$ Cathia Maria Barrientos Serra, ${ }^{* *}$ Flavio Fernando Batista Moutinho, ${ }^{* *}$ \\ Luiz Ricardo de Andrade Pontes***
}

\begin{abstract}
Resumo
Cimex lectularius ("percevejo-de-cama") é um hemíptero da família Cimicidae que normalmente parasita seres humanos. Descrevese uma infestação por esta espécie em uma escola rural do município de Duas Barras, estado do Rio de Janeiro, associada a relatos de queixas de irritação e prurido por parte de alguns indivíduos da comunidade escolar. Durante a inspeção do local, os insetos foram encontrados no forro do estabelecimento junto a sujidades e penas de psitacídeos, sendo posteriormente identificados como Cimex lectularius. A confirmação da colonização de espécie de hemíptera hematófago no forro do estabelecimento escolar inspecionado serve de alerta às autoridades para melhoria na construção e manutenção das edificações públicas, em especial escolas, hospitais, asilos e penitenciárias. Esforços deverão ser feitos para se conhecer a real magnitude do parasitismo por $C$. lectularius no Brasil, tendo em vista seu grande potencial endofílico e de dispersão.
\end{abstract}

Palavras-chave: Cimex lectularius, parasitismo, humanos, percevejo de cama.

\begin{abstract}
The Cimex lectularius ("bed bug") is a hemipterus of the Cimicidae family. It is usually a human being parasite. An infestation by that species is reported to have taken place at a rural school in the municipality of Duas Barras, in the State of Rio de Janeiro. Some individuals of the school community complained about itching and irritation. During an onsite inspection insects were found in the building's ceiling, together with dirt and parrot feathers. They were subsequently identified as Cimex lectularius. The confirmation of colonization by a blood hemipterus species at the inspected school ceiling should serves as a warning to the authorities, so that they may improve the construction and maintenance of public buildings, especially, schools, hospitals, care centers and prisons. Efforts should be made to learn about the actual magnitude of parasitism by $C$. lectularius in Brazil, taking into consideration its great endophilic and dissemination potential.
\end{abstract}

Keywords: Cimex lectularius, parasitism, humans, bedbugs.

\section{Introdução}

Os cimicídeos são divididos em seis subfamílias, 23 gêneros e 91 espécies (RYCKMAN et al., 1981; FORATTINI, 1990). Dessas 91 espécies, apenas três podem ser consideradas ectoparasitos verdadeiros de homem, sendo vulgarmente conhecidas como percevejos-de-cama: Cimex lectularius, Cimex hemipterus e Leptocimex boueti (USINGER, 1966; RYCKMAN et al.,1981; FORATTINI, 1990). Na ausência de sangue humano, porém, podem vir a parasitar roedores e outros animais domésticos (THOMAS et al., 2004). Algumas espécies dessa família são ectoparasitos de morcegos e aves e eventualmente podem sugar o sangue humano, sem fazer dele seu hospedeiro natural (EADS et al., 1980; RYCKMAN et al., 1981; FORATTINI, 1990).
Segundo Burton (1963), estes insetos já foram encontrados naturalmente infectados por diversos agentes patogênicos e mostraram-se suscetíveis em infecções experimentais a alguns vírus, bactérias e protozoários. Apesar destes achados, não foi possível ainda incriminá-los na transmissão natural de nenhum patógeno para o homem (GODDARD; SHAZO, 2009).

A importância de Cimex lectularius tem sido relacionada essencialmente com o seu hábito domiciliado, podendo a infestação do ambiente humano atingir níveis elevados (FORATTINI, 1990) e estar associada à infecção bacteriana secundária no local da picada e alergia (BESNOIT et al., 2007). A infestação crônica pode causar nervosismo, ansiedade e insônia (THOMAS et al., 2013).

* Recebido em 28 de maio de 2014 e aceito em 28 de abril de 2015

**Universidade Federal Fluminense - Faculdade de Veterinária - Departamento de Saúde Coletiva Veterinária e Saúde Pública. Niterói, RJ, Brasil.

***Prefeitura Municipal de Duas Barras - Secretaria Municipal de Saúde - Divisão de Fiscalização Sanitária - Duas Barras, RJ, Brasil.

Autor para correspondência: flaviomoutinho@id.uff.br 
Diante da problemática, esta nota tem como objetivo registrar o parasitismo humano por $C$. lectularius em zona rural, sob condições que divergem de seu comportamento biológico normal.

\section{Relato do caso}

No mês de março de 2014, a Divisão de Fiscalização Sanitária do município de Duas Barras, estado do Rio de Janeiro, visitou uma escola estadual do referido município, após notificação da diretora do estabelecimento. A escola se localiza na zona rural, funcionando em dois turnos (manhã e tarde), atendendo à comunidade local nos segmentos de Educação Infantil, Pré-escola e Ensino Fundamental. O motivo da visita estava relacionado, segundo os usuários, com a queixa sobre "um inseto não identificado (...) que tem causado irritação e coceira na pele de funcionários e alunos, sendo que alguns deles precisaram ser medicados, pois ocorreram reações alérgicas".

Durante a inspeção, os funcionários da escola relataram que os insetos foram observados pela primeira vez no verão de 2013, durante o dia, sendo facilmente visualizados nas paredes, banheiros, depósito e cozinha.

Esses funcionários afirmaram, ainda, que psitacídeos comumente constroem ninhos no forro do estabelecimento e que, mesmo na ausência das aves, em fevereiro de 2014, a visualização dos insetos foi constante, principalmente nas horas mais quentes do dia.

$O$ forro do estabelecimento foi inspecionado pelos agentes de saúde e constatou-se a presença de acúmulo de terra, penas características de aves esverdeadas, pedaços de papel e outros materiais e detritos, onde foram coletados inúmeros exemplares do referido inseto (Figura 1).

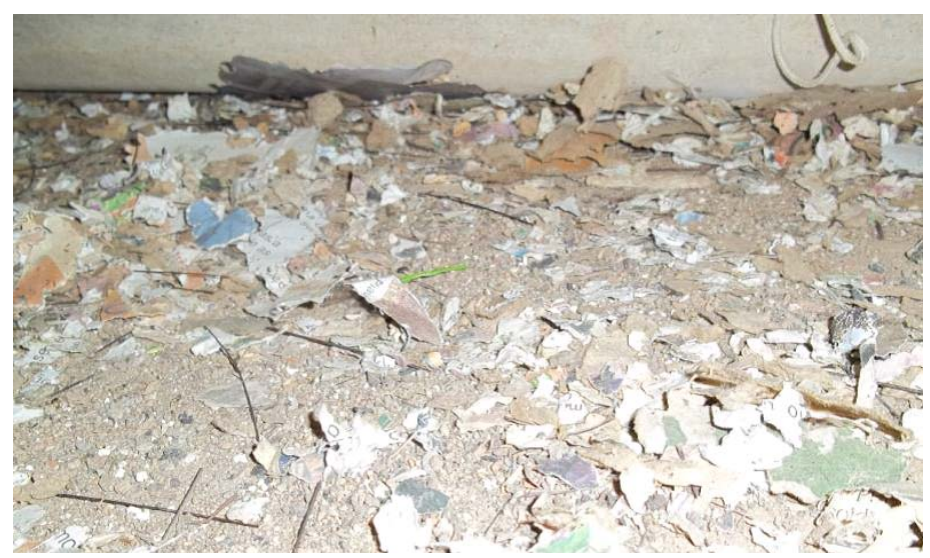

Figura 1: Detritos sobre o forro do telhado da escola pública, Duas Barras, RJ, 2014.

O material coletado foi depositado em álcool $70 \%$ e encaminhado ao Laboratório de Doenças Parasitárias do Departamento de Saúde Coletiva Veterinária e Saúde Pública da Faculdade de Veterinária da Universidade Federal Fluminense, onde foram identificados como percevejos Cimex lectularius
(Hemiptera:Cimicidae) em diferentes estágio de desenvolvimento (Figura 2).

igura 2: Exemplares de Cimex lectularius (Hemiptera: Cimicidae) coletados no local da infestação (um adulto na figura $2 \mathrm{~A}$ e três ninfas na figura $2 \mathrm{~B}$ ).

A identificação de $C$. lectularius baseou-se nos aspectos morfológicos que o caracterizam e diferem de outras espécies do gênero. Esse inseto possui protórax largo e de contorno regular, apresentando expansão lateral variavelmente desenvolvida e a margem anterior côncava, onde se encaixa a cabeça (FORATTINI, 1990).

Após o diagnóstico procedeu-se à orientação de medidas de controle às autoridades competentes, tais como retirada e limpeza do forro do estabelecimento e desinsetização por empresa licenciada pelo Instituto Estadual do Ambiente.

\section{Discussão}

Cimex lectularius tem sido reconhecido como um parasito humano há milhares de anos, mas estudos científicos deste inseto são recentes e limitados (REINHARTDT; SIVA-JOTHY, 2007; POTTER, 2006). A infestação por percevejos vem sendo relatada, cada vez mais, em casas, apartamentos, quartos de hotel, hospitais e dormitórios, nos Estados Unidos, desde 1980 (KING et al.; 1989; HARLAN, 2006; POTTER, 2006). Segundo HWANG et al. (2005) o ressurgimento do $C$. lectularius vem afetando outros países, como o Canadá, onde especialistas em Saúde Pública registraram um aumento de $100 \%$ nas reclamações telefônicas sobre percevejos durante um período de seis meses em 2002. Na Alemanha, a infestação de percevejos aumentou de cinco casos em 1992 para 76 casos em 2004 (BAUERDUBAU, 2004). Na Austrália, amostras de percevejos encaminhados aos órgãos públicos aumentaram em $400 \%$ durante o período de 2001 a 2004, em comparação com 1997 a 2000 (DOGGET et al., 2004). Viagens internacionais, imigração, mudanças nas práticas de controle de pragas e resistência aos inseticidas podem ter contribuído para esse ressurgimento do percevejo nesses países desenvolvidos (POTTER, 2006; ROMERO et al. 2007).

As campanhas nacionais de controle de vetores de doenças como febre amarela, dengue, doença de chagas e malária acabaram por controlar, indiretamente, as infestações de cimicídeos no Brasil, levando à drástica redução de sua 
ocorrência no século passado, com sinais de re-emergência a partir da década de 1990 (JUSTI JÚNIOR; CAMPOS, 2014). Apesar disso, Criado et al. (2011) assinalam a escassez na literatura sobre a infestação por cimicídeos no Brasil e que provavelmente haja sub-notificação de sua ocorrência na literatura médica.

No presente caso, foi fundamental a notificação realizada pela diretora da escola, desencadeando a inspeção sanitária e possibilitando a investigação da causa do problema. É comum os cimicídeos se abrigarem nos mesmos locais onde habitam a fonte de alimentação sanguínea (FORATTINI, 1990), que no caso observado neste estudo possivelmente eram os psitacídeos e os humanos que frequentavam a unidade de ensino. O forro com fragmentos de pena, papel e outros detritos, como o encontrado, pode ser considerado um abrigo adequado para esses insetos já que, de acordo com Justi Júnior \& Campos (2014), eles parecem preferir superfícies de madeira e papel, dentre outros materiais.

Apesar dos cimicídeos apresentarem mobilidade apreciável quando em busca de alimentação, a dispersão passiva por intermédio de aves e quirópteros tem grande importância para grandes percursos (FORATTINI, 1990). O mesmo se dá com o transporte passivo, meios de transporte, malas, bolsas, roupas e móveis usados (JUSTI JÚNIOR; CAMPOS, 2014).

\section{Referências}

BAUER-DUBAU, K. Invasion in deutschen Betten: Bettwanzen. 2004. Disponível em: http://www.hautstadt.de/hs/pages/news/ list_news.php?we_objectlD=3779. Acesso em 23 maio, 2014.

BENOIT, J. B.; DEL GROSSO, N. A.; YODER, J. A.; DENLINGER, D. L. Resistance to dehydration between bouts of blood feeding in the bedbug, Cimex lectularius, is enhanced by water conservation, aggregation, and quiescence. Am J Trop Med Hyg, v. 76, n. 5, p. 987-93, 2007.

BURTON, G. J. Bedbugs in relation to transmission of human diseases. Review of the literature. Pub Health Rep. v. 78, p. 51324, 1963.

CRIADO, P. R.; BELDA JÚNIOR, W.; CRIADO,R. F. J.; VASCONCELOS E SILVA, R..; VASCONCELLOS, C. Bedbugs (Cimicidae infestation): the worldwide renaissance of an old partner of human kind. Braz J Infect Dis, v. 15, n. 1, p. 74-80, 2011.

DOGGETT, S.; GREARY, M.; RUSSELL, R. The resurgence of bed bugs in Australia. Environ Health., v. 4, p. 30-38, 2004.

EADS, R. B.; FRANCY, D. B.; SMITH, G. C. The swallow bug, Oeciacus vicarious Horvath (Hemiptera: Cimidae), a human house hold pest. Proc. Entomol. Soc., v. 82, p. 81-85, 1980.

FORATTINI, O. P. Os cimicídeos e sua importância em saúde pública (Hemiptera-Heteroptera: Cimicidae). Rev Saúde Pública. v. 24, Supl., p.1-37, 1990.

GODDARD, J., DE SHAZO, R. D. Bedbugs (Cimex lectularius) and clinical consequences of their bites. JAMA, v. 301, n. 13, p.1358-1366, 2009.

HARLAN, H. J. Bed bugs 101: the basics of Cimex lectularius. Am Entomol., v. 52, p. 99-101, 2006. Disponível em: http://www. afpmb.org/sites/default/files/whatsnew/2006/harlan.pdf. Acesso em 23 maio, 2014.
Devido à sua endofilia e capacidade de dispersão passiva a grandes distâncias do seu local de origem (FORATTINI,1990), a implementação precoce das ações sanitárias em cada foco notificado estará contribuindo não somente para o caso em questão mas também evitando que este parasitismo se torne um maior problema de Saúde Pública em nosso país.

Informações sobre os cimicídeos deveriam ser mais disseminadas entre diferentes setores da sociedade, o que aumentaria o nível de conhecimento da população e dos profissionais de saúde para suspeitarem de sua presença.

\section{Conclusões}

A confirmação da colonização de espécie de hemíptera hematófaga no forro do estabelecimento escolar inspecionado serve de alerta às autoridades para melhoria na construção e manutenção das edificações públicas, em especial escolas, hospitais, asilos e penitenciárias. Deve-se dar prioridade a eliminar situações que propiciem o acesso e instalação de populações animais como morcegos, aves, roedores e insetos, o que evitará riscos à Saúde Pública e gastos com o desalojamento destas espécies. Esforços deverão ser feitos para se conhecer a real magnitude do parasitismo por C.lectularius no Brasil, tendo em vista seu grande potencial endofílico e de dispersão.

HWANG, S. W.; SVOBODA, T. J.; DE JONG, I. J.; KABASELE, K. J.; GOGOSIS, E. Bed bug infestations in an urban environment. Emerg Infect Dis., v. 11, n. 4, p. 533-538, 2005.

JUSTI JUNIOR, J.; CAMPOS, A. E. C.; Perguntas e respostas sobre percevejos-de- cama (Hemiptera:Cimicidae): consultas atendidas pelo Instituto Biológico. Biológico, São Paulo, v.76, n.1, p. 63-67, jan./jun., 2014.

KING, F.; DICK, I.; EVANS, P. Bed bugs in Britain. Parasitol Today, v. 5, p.100-102, 1989.

POTTER, M. F. The perfect storm: an extension view on bed bugs. Am Entomol. v. 52, p.102-104, 2006. Disponível em: http:// www.entsoc.org/PDF/Pubs/Periodicals/AE/AE-2006/Summer/ Potter.pdf. Acesso em 23 maio 2014.

REINHARDT, K., SIVA-JOTHY, M. T. Biology of the bed bugs (Cimicidae). Annu Rev Entomol. v.52, p. 351-374, 2007.

ROMERO, A.; POTTER, M. F.; POTTER, D. A.;, HAYNES, K. $F$. Insecticide resistance in the bed bug: a factor in the pest/s sudden resurgence? J Med Entomol, v. 44, n. 2, p. 175-178, 2007.

RYCKMAN, R. E.; BENTLY, D. G.; ARCHBOLD, E. F. The Cimicidae of the Americas and Oceanic Islands, a checklist and bibliography. Bull. Soc. Vector. Ecol., v 6, p. 93-142, 1981.

THOMAS, I.; KIHICZAK, G. G.; SCHWARTZ, R. A. Bedbug bites: a review. Int. J. Dermatol., v. 43, p. 430-433, 2004.

THOMAS, S.; WROBEL, M. J.; BROWN, J. Bedbugs: A primer for the health-system pharmacist. Am.J.Health-Syst Pharm., v.70, p.126-130, 2013.

USINGER, R. L. Monograph of Cimicidae, v. 7. Baltimore: The Thomas Say Foundation, 1966. 585 p. 